\title{
Clinical outcome 5 to 18 years after the Fontan operation performed on children younger than 5 years
}

\author{
Daniëlle Robbers-Visser, MD, ${ }^{\mathrm{a}, \mathrm{b}}$ Livia Kapusta, $\mathrm{MD}, \mathrm{PhD},{ }^{\mathrm{g}}$ Lennie van Osch-Gevers, MD, PhD, ${ }^{\mathrm{a}}$ \\ Jan L. M. Strengers, MD, PhD, ${ }^{\mathrm{h}}$ Eric Boersma, $\mathrm{PhD},{ }^{c}$ Yolanda B. de Rijke, $\mathrm{PhD},{ }^{\mathrm{d}}$ Frans Boomsma, PhD, ${ }^{\mathrm{e}}$ \\ Ad J. J. C. Bogers, MD, PhD, ${ }^{f}$ and Willem A. Helbing, $\mathrm{MD}, \mathrm{PhD}^{\mathrm{a}, \mathrm{b}}$
}

Objective: This study assessed clinical condition at midterm follow-up after total cavopulmonary connection for a functionally univentricular heart performed on children younger than 5 years.

Methods: Thirty-four Fontan patients (median age 10.4 years, range 6.8-20.7 years, 22 boys, median follow-up 7.8 years, 5.0-17.8 years) underwent electrocardiography, Holter monitoring, bicycle exercise testing, cardiac magnetic resonance imaging, and N-terminal prohormone brain natriuretic peptide (NT-pro-BNP) analysis.

\begin{abstract}
Results: Twenty-three patients $(68 \%)$ were in sinus rhythm. Holter monitoring demonstrated normal mean heart rate, low maximal heart rate, and no clinically significant arrhythmias or sinus node dysfunction. With maximal bicycle ergometry $(\mathrm{n}=19)$, maximum workload $(60 \%$ of normal), maximum heart rate $(90 \%$ of normal), and maximal oxygen uptake ( $69 \%$ of normal) were all significantly lower in the Fontan group than in a control group $(P<.001)$. Variables of submaximal exercise indicated less efficient oxygen uptake during exercise in all Fontan patients. Ejection fraction was lower than in control subjects $(59 \% \pm 13 \%$ vs $69 \% \pm 5 \%, P<.001)$. Mean enddiastolic and end-systolic volumes and ventricular mass were higher than in control subjects $(P<.001)$. Mean NT-pro-BNP levels were increased relative to reference values, but only 8 patients had levels above the upper reference limit.
\end{abstract}

Conclusion: At midterm follow-up, Fontan patients were in acceptable clinical condition, with preserved global ventricular function, moderately decreased exercise capacity, and NT-pro-BNP levels within reference range. Systemic ventricular mass was elevated, however, suggesting contractility-afterload mismatch. Long-term consequences for ventricular function merit further investigation.

Earn CME credits at

http://cme.ctsnetjournals.org
The Fontan operation is a palliative procedure for patients with a congenital heart defect that precludes biventricular repair. These days, it is performed as a staged procedure resulting in redirection of the systemic venous return to the pulmonary circulation without interposition of a subpulmonary ventricle. There have been important modifications of the original concept, aimed at improving systemic venous and pulmonary artery hemodynamics and at preventing late

\footnotetext{
From the Department of Pediatrics, Division of Cardiology, Erasmus MC-Sophia Children's Hospital, ${ }^{a}$ Rotterdam, The Netherlands; the Departments of Radiology, ${ }^{\text {b }}$ Cardiology ${ }^{\mathrm{c}}$ Clinical Chemistry, ${ }^{\mathrm{d}}$ Internal Medicine, ${ }^{\mathrm{e}}$ and Cardiothoracic Surgery, ${ }^{\mathrm{f}}$ Erasmus MC, Rotterdam, The Netherlands; Children's Heart Center, UMC St Radboud ${ }^{\mathrm{g}}$ Nijmegen, The Netherlands; and the Department of Pediatric Cardiology, University MC Utrecht—Wilhelmina Children's Hospital, ${ }^{\text {h }}$ Utrecht, The Netherlands.

Received for publication July 15,2008 ; revisions received Dec 11, 2008; accepted for publication Dec 25, 2008.

Address for reprints: W. A. Helbing, MD, PhD, Erasmus MC-Sophia Children's Hospital, Department of Paediatric Cardiology, Sp-2429, PO Box 2060, 3000 CB

Rotterdam, The Netherlands (E-mail: w.a.helbing@erasmusmc.nl).

J Thorac Cardiovasc Surg 2009;138:89-95

$0022-5223 / \$ 36.00$

Copyright (c) 2009 by The American Association for Thoracic Surgery

doi:10.1016/j.jtcvs.2008.12.027
}

sequelae. ${ }^{1}$ Currently, total cavopulmonary connection (TCPC), with either an intra-atrial lateral tunnel or an extracardiac conduit to connect the inferior caval vein to the pulmonary artery, is the procedure of choice.

Morbidity and mortality have improved significantly in recent years ${ }^{2}$; however, information on midterm and longterm outcomes after Fontan operation according to current techniques is sparse, because these patients are only just reaching adolescence and adulthood. Although there are several reports on clinical outcome after the Fontan operation, ${ }^{2-4}$ most of these retrospective studies include relatively heterogeneous patient groups, with heterogeneous treatment strategies. The results in these reports thus may not be applicable to patients who have undergone Fontan completion in the present era. Today's policy, for example, is to perform the TCPC at increasingly younger ages.

The objective of this study was to assess 5-year and later clinical follow-up in a cohort of patients after TCPC at young age, 5 years or younger. For this purpose, we performed electrocardiography, bicycle exercise testing, assessment of ventricular function with magnetic resonance imaging (MRI), and assessment of $\mathrm{N}$-terminal prohormone brain natriuretic peptide (NT-pro-BNP). The last is known to discriminate pediatric patients with cardiac disease and closely correlates with ventricular function. ${ }^{5}$ 


$\begin{array}{ll}\text { Abbreviations and Acronyms } \\ \text { BNP } & =\text { brain natriuretic peptide } \\ \text { EDVI } & =\text { end-diastolic volume index } \\ \text { EF } & =\text { ejection fraction } \\ \text { ESVI } & =\text { end-systolic volume index } \\ \text { LV } & =\text { left ventricle } \\ \text { MRI } & =\text { magnetic resonance imaging } \\ \text { NT-pro-BNP } & =\text { N-terminal prohormone } \\ & \text { brain natriuretic peptide } \\ \text { OUES } & =\text { oxygen uptake efficiency slope } \\ \text { RQ } & =\text { respiratory quotient } \\ \text { RV } & =\text { right ventricle } \\ \text { TCPC } & =\text { total cavopulmonary connection } \\ \dot{\mathrm{V}}_{\mathrm{E}} & =\text { pulmonary ventilation } \\ \dot{\mathrm{V}}_{\mathrm{O}_{2}} & =\text { oxygen consumption } \\ \end{array}$

\section{MATERIALS AND METHODS Patients}

A cross-sectional study of patients after Fontan completion was performed. The following inclusion criteria were used: (1) initial Fontan completion (TCPC) between 1988 and 2001, with regular follow-up, at three tertiary pediatric referral centers, (2) age at Fontan completion of 5 years or younger, and (3) duration of follow-up since Fontan completion of at least 5 years. Exclusion criteria were as follows: (1) contraindications for MRI or bicycle exercise testing and (2) inadequate communication, either because of mental retardation or because of a language barrier. Medical records were reviewed for patient characteristics and anatomic and operative details. The study was approved by the Dutch Central Committee on Research involving Human Subjects and all three institutional review boards. All subjects, and/or their parents if required, gave informed consent.

\section{Electrocardiography}

A standardized 12-lead electrocardiogram was obtained for all patients to determine rhythm status, QRS duration (in milliseconds), and QT interval corrected for heart rate (in milliseconds). A 24-hour Holter monitoring was performed in all patients on a day with usual activities.

\section{Bicycle Exercise Testing}

A Jaëger Oxycon Champion System (Viasys Healthcare, Hoechberg, Germany), allowing breath-by-breath ergometry, was used for maximal exercise testing. Subjects were continuously monitored with 12-lead electrocardiography and blood pressure measurements. Workload increased stepwise with 10 to $20 \mathrm{~W} / \mathrm{min}$. For bicycle exercise testing, a group of 32 sex- and height-matched control subjects was selected. Patients and control subjects were encouraged to perform until exhaustion, defined as a respiratory quotient (RQ) at peak exercise of at least 1.05. Twenty-eight control subjects and 19 Fontan patients managed to perform until the RQ reached or exceeded 1.05. Eight patients with a submaximal exercise test did reach RQs of at least 1.00 . The patients with RQs less than 1.05 were younger than those with RQs of at least $1.05(10.0 \pm 2.5$ years vs $13.2 \pm 3.7$ years, $P=.011)$. In the control group, subjects with RQs less than 1.05 were also younger than subjects with RQs of at least $1.05(8.9 \pm 0.8$ years vs $12.7 \pm 3.4$ years, $P<.001)$.

In all patients and control subjects, two variables of submaximal exercise were assessed: (1) the slope of oxygen uptake versus exercise intensity, according to the method of Reybrouck and colleagues, ${ }^{6}$ and (2) the oxygen uptake efficiency slope (OUES), according to the method of Baba and coworkers, ${ }^{7}$ as the linear relationship between $\log$ of pulmonary ventilation $(\dot{\mathrm{V}} \mathrm{E})$ and oxygen consumption $\left(\dot{\mathrm{V}}_{2}\right)$. These two variables are a measure of the efficiency of the system in extracting oxygen during exercise and of use in the periphery. A higher slope indicates a more efficient oxygen uptake. Because Giardini and associates ${ }^{8}$ recently reported nonlinearity of the relationship between the log of $\dot{\mathrm{V}}_{\mathrm{E}}$ and $\dot{\mathrm{V}}_{\mathrm{o}_{2}}$ throughout the exercise test for hypoxemic patients who have undergone the Fontan operation, we first validated the linearity of this relationship for patients who performed a maximal exercise test. Maximum workload (in watts), maximum heart rate (in beats per minute), and maximum $\dot{\mathrm{V}}_{2}\left(\dot{\mathrm{V}}_{\mathrm{O}_{2}} \mathrm{max}\right.$ in milliliters per kilogram per minute) were obtained for patients and control subjects with RQs of at least 1.05 .

\section{Magnetic Resonance Imaging}

Cardiac MRI was performed in all patients on a Signa 1.5-T whole-body MRI system (General Electric, Milwaukee, Wis). Dedicated phased-array cardiac surface coils were placed over the thorax. Patients were monitored by vector cardiographic gating and blood pressure monitoring.

A multiphase, multislice volumetric data set was acquired with a fast 2-dimensional cine scan that used steady-state free precession. From 10 to 12 contiguous slices were planned parallel to the atrioventricular valve plane of the systemic ventricle to cover the heart from base to apex. Imaging parameters were as follows: slice thickness 7 to $10 \mathrm{~mm}$, interslice gap $0 \mathrm{~mm}$, field of view 280 to $370 \mathrm{~mm}$, phase field of view 0.75 , matrix $160 \times$ $128 \mathrm{~mm}$, repetition time $3.5 \mathrm{~ms}$, echo time $1.5 \mathrm{~ms}$, flip angle $45^{\circ}$, and mean in-plane resolution $2 \mathrm{~mm}^{2}$. All images were acquired without breath holding and were built up during multiple heart beats to eliminate the effects of respiration on caval vein and pulmonary artery flow dynamics, with 3 signal averages.

Analysis was performed with a commercially available Advanced Windows workstation (General Electric Medical Systems). The ventricular volumetric data set was quantitatively analyzed with the AW 5.1 version of the MR Analytical Software System (Medis Medical Imaging Systems, Leiden, The Netherlands). With manual detection of endocardial and epicardial borders in end-systole and end-diastole, the following parameters were calculated: end-diastolic and end-systolic volumes indexed for body surface area (EDVI and ESVI, respectively), stroke volume index, ejection fraction (EF), and systemic ventricular mass index. Ventricular volumes and masses were defined as the sum of the volumes and masses of the systemic ventricle and any hypoplastic chamber present. Data were compared with reference data from 60 healthy children aged 8 to 17 years. ${ }^{9}$

\section{NT-pro-BNP Analysis}

Blood samples were taken from a peripheral vein after 30 minutes' rest in the supine position. Plasma and serum were separated immediately after sample collection and stored at $-80^{\circ} \mathrm{C}$. NT-pro-BNP was measured with the Elecsys electrochemiluminescence immunoassay (Roche Diagnostics, Mannheim, Germany). We preferred the determination of NT-pro-BNP for its stability in whole blood, its independence from exercise and position, and its longer half-life in serum than brain natriuretic peptide (BNP) itself. ${ }^{10}$ Data were compared with reference data from a study that used an identical analysis method. ${ }^{10,11}$ Expected mean values were calculated according to the following equation ${ }^{10}$ : NT-pro-BNP $=-0.3707 \times$ age +12.346 . The upper reference limit was defined as the 97.5 th percentile from the study of Albers and coworkers. ${ }^{11}$

\section{Statistical Analysis}

Continuous data were tested for normality with the KolmogorovSmirnov test. Values of NT-pro-BNP were $\log _{10}$ transformed to obtain approximately normal distribution. Data with a normal distribution are expressed as mean $\pm \mathrm{SD}$, whereas the median and range are shown for data with a nonnormal distribution. Differences in continuous data between groups of patients were evaluated with the Student $t$ test, or 
with nonparametric tests for small subgroups. Dichotomous data are presented as counts and percentages, and differences between groups of patients were evaluated with $\chi^{2}$ or Fisher exact tests, as appropriate. Univariable regression analyses were performed to study the interrelation of NT-pro-BNP with the following: (1) demographic variables, (2) measures of systemic ventricular function and volumes acquired with CMR imaging, and (3) physical exercise response. They were also performed to study the relationship between ventricular mass and EF. Analyses were performed with the SPSS-PC statistical software package version 14.0 (SPSS, Inc, Chicago, Ill).

\section{RESULTS \\ Patients}

We identified 100 patients who had undergone a TCPC in the period between 1988 and 2001 and were alive at the start of the study. The following patients were excluded: (1) 23 patients with Fontan completion at an age later than 5 years, (2) 8 patients with pacemaker placement, (3) 5 patients with hemiplegia or quadriplegia, (4) and 10 patients with inadequate communication. Of 54 eligible patients, 34 patients ( 22 boys) participated in this study. There were no differences between participants and nonresponders in patient, procedural, and follow-up characteristics.

Median age was 10.4 years (6.8-22.2 years). Mean age at Fontan completion was $3.0 \pm 1.1$ years. Median weight was $13.9 \mathrm{~kg}(8.9-22.0 \mathrm{~kg})$. Median follow-up after Fontan completion was 7.8 years (5.0-17.1 years). Twenty-seven patients had an intra-atrial lateral tunnel; 7 patients had an extracardiac conduit. Most patients $(n=28,82 \%)$ had undergone staged procedures, with a bidirectional Glenn anastomosis before completion of the Fontan circulation at a median age of 1.0 years ( $0.2-3.8$ years). Median interval between bidirectional Glenn shunt and Fontan completion was 1.7 years ( $0.5-3.3$ years). Four patients had fenestrated TCPCs because of hemodynamic indications. In 1 case the fenestration closed spontaneously; another patient underwent catheter-based closure of the fenestration.

The dominant ventricle was a morphologically right ventricle (RV) in 16 patients, 6 of whom had hypoplastic left heart syndrome. The dominant ventricle was a morphologically left ventricle (LV) in 17 patients, 7 of whom had tricuspid atresia. In 1 patient, ventricular morphology could not be determined. There was 1 patient with right isomerism and 1 patient with left isomerism, with normal systemic venous connections.

Most patients $(\mathrm{n}=21)$ had a normal resting oxygen saturation of at least $95 \%$; however, 10 patients were mildly hypoxemic (oxygen saturation $90 \%-94 \%$ ) and 3 patients had an oxygen saturation below $90 \%$ ( 2 with fenestrated intra-atrial lateral tunnels, the other with a baffle leak after an unfenestrated Fontan operation). The New York University pediatric heart failure index ${ }^{12}$ (score of 0 meaning no heart failure, score of 30 meaning severe heart failure) was between 4 and 9 in this patient group. Five patients were receiving angiotensin-converting enzyme inhibitors, and no patients were receiving diuretics or antiarrhythmic medication.

\section{Electrocardiography}

Twenty-three patients were in sinus rhythm. Nine patients had a supraventricular rhythm, and in 2 patients the rhythm was of atrioventricular nodal origin. Mean QRS duration was $100 \pm 13 \mathrm{~ms}$. Mean QT interval corrected for heart rate was $419 \pm 26 \mathrm{~ms}$. There was no difference in QRS duration and QT interval corrected for heart rate between patients with a dominant RV and those with a dominant LV.

None of the patients had any symptoms during 24-hour Holter monitoring. Thirty patients showed sinus rhythm, with frequent episodes of supraventricular rhythm in 2 patients and occasional episodes of supraventricular rhythm in 12 patients. Two patients had occasional episodes with a junctional rhythm. Mean heart rate was $79 \pm 12$ beats/ min. Mean maximum heart rate was $168 \pm 18$ beats/min (128-200 beats/min), and mean minimum heart rate was $46 \pm 9$ beats/min (33-67 beats/min). There was no difference between patients with a lateral tunnel and patients with an extracardiac conduit (Table 1). There were no cardiac pauses longer than 1.9 seconds. Only 1 patient (age 17 years, 16 years after Fontan completion for hypoplastic left heart syndrome) had frequent premature atrial contractions. Shortly after the investigations for this study, this patient had atrial flutter.

\section{Bicycle Exercise Testing}

Bicycle exercise testing was successfully completed by 32 patients and all control subjects. One patient (age 6.8 years, height $117 \mathrm{~cm}$ ) was too small for our ergometer. Breath-bybreath analysis failed because of a technical problem in 1 other case.

Relative to the control group $(\mathrm{n}=28)$, Fontan patients $(\mathrm{n}=19)$ reached a lower maximum workload $(60 \%$ of control subjects, $146 \pm 61 \mathrm{~W}$ vs $87 \pm 30 \mathrm{~W}, 3.2 \pm$ $0.6 \mathrm{~W} / \mathrm{kg}$ vs $2.1 \pm 0.5 \mathrm{~W} / \mathrm{kg}, P<.001)$ and lower maximum heart rate $(90 \%$ of control subjects, $184 \pm 12$ beats/min vs $166 \pm 15$ beats $/ \mathrm{min}, P=.001) . \dot{\mathrm{V}}_{2} \max$ was significantly lower in Fontan patients $(69 \%$ of control subjects, $48 \pm 7 \mathrm{~mL} /(\mathrm{min} \cdot \mathrm{kg})$ vs $33 \pm 8 \mathrm{~mL} /(\mathrm{min} \cdot \mathrm{kg})$, $P<.001)$.

Among patients who completed a maximal exercise test $(n=19)$, there was no difference between OUES for the entire exercise test and OUES during the second half of the test $(1.57 \pm 0.38$ and $1.50 \pm 0.57$, respectively, $P=.38)$. OUES during the first half of the test $(1.46 \pm 0.38)$ was lower than OUES of the entire test $(P=.046)$. In hypoxemic patients, this comparison of OUES yielded the same results. The relationship between the log of $\dot{\mathrm{V}} \mathrm{E}$ and $\dot{\mathrm{V}}_{\mathrm{O}_{2}}$ was not considered linear, but OUES of the second half of the test was considered to be representative of the OUES of the complete test. 
TABLE 1. Comparison of outcome variables between different types of Fontan operation

\begin{tabular}{|c|c|c|c|}
\hline Variable & ILT & ECC & $P$ value \\
\hline Age (y, median and range) & $10.3(6.8-20.7)$ & $10.3(8.0-14.1)$ & .90 \\
\hline Age at Fontan completion (y, median and range) & $2.9(1.0-5.0)$ & $2.8(2.3-4.1)$ & .56 \\
\hline Follow-up (y, median and range) & $7.7(5.0-17.1)$ & $7.9(5.2-10.0)$ & .84 \\
\hline Oxygen saturation at rest ( $\%$, median and range) & $95 \%(87 \%-100 \%)$ & $97 \%(95 \%-98 \%)$ & .14 \\
\hline \multicolumn{4}{|l|}{ Blood pressure at rest $(\mathrm{mm} \mathrm{Hg}$, mean $\pm \mathrm{SD}$ ) } \\
\hline Systolic & $110 \pm 7$ & $133 \pm 9$ & .013 \\
\hline Diastolic & $77 \pm 15$ & $73 \pm 6$ & .83 \\
\hline NT-pro-BNP (pmol/L, median and range) & $13(3-57)$ & $7(4-37)$ & .06 \\
\hline OUES (mean $\pm \mathrm{SD}$ ) & $1.55 \pm 0.52$ & $1.66 \pm 0.37$ & .72 \\
\hline OUEIS $($ mean \pm SD) & $8.8 \pm 1.3$ & $10.0 \pm 1.2$ & .59 \\
\hline $\mathrm{EDVI}\left(\mathrm{mL} / \mathrm{m}^{2}\right.$, mean $\left.\pm \mathrm{SD}\right)$ & $78 \pm 15$ & $79 \pm 16$ & .22 \\
\hline $\operatorname{ESVI}\left(\mathrm{mL} / \mathrm{m}^{2}\right.$, mean $\left.\pm \mathrm{SD}\right)$ & $36 \pm 17$ & $24 \pm 6$ & .13 \\
\hline Ventricular mass index $\left(\mathrm{g} / \mathrm{m}^{2}\right.$, mean $\left.\pm \mathrm{SD}\right)$ & $70 \pm 16$ & $73 \pm 7$ & .79 \\
\hline Ejection fraction $(\%$, mean $\pm \mathrm{SD})$ & $56 \% \pm 14 \%$ & $69 \% \pm 4 \%$ & .019 \\
\hline \multicolumn{4}{|l|}{ Heart rate (beats/min, mean $\pm \mathrm{SD}$ ) } \\
\hline Mean & $77 \pm 13$ & $79 \pm 14$ & .71 \\
\hline Maximum & $161 \pm 16$ & $175 \pm 9$ & .28 \\
\hline Minimum & $46 \pm 10$ & $47 \pm 8$ & .79 \\
\hline
\end{tabular}

ILT, Intra-atrial lateral tunnel; $E C C$, extracardiac conduit; $N S$, not significant; $N T$-pro-BNP, $\mathrm{N}$-terminal prohormone brain natriuretic peptide; OUES, oxygen uptake efficiency slope; OUEIS, oxygen uptake/exercise intensity slope; EDVI, end-diastolic volume index; ESVI, end-systolic volume index.

Both variables of submaximal exercise were higher in control subjects $(\mathrm{n}=32)$ than in patients $(\mathrm{n}=32)$. The OUES was $2.00 \pm 0.66)$ in control subjects and $1.50 \pm$ 0.44 in patients $(P=.002)$. The slope of oxygen uptake versus exercise intensity was $9.7 \pm 0.9$ ) in control subjects and $8.9 \pm 1.3$ in Fontan patients $(P=.004)$.

There was no difference between patients with a dominant $\mathrm{RV}$ and patients with a dominant $\mathrm{LV}$ in variables of maximal exercise $(8 \mathrm{RV}, 10 \mathrm{LV})$ and submaximal exercise (14 RV, $17 \mathrm{LV})$. There were also no differences between different Fontan types.

\section{Magnetic Resonance Imaging}

Mean EDVI was $77 \pm 16 \mathrm{~mL} / \mathrm{m}^{2}$, mean ESVI was $33 \pm$ $14 \mathrm{~mL} / \mathrm{m}^{2}$, mean EF was $59 \% \pm 12 \%$, and mean mass index was $71 \pm 19 \mathrm{~g} / \mathrm{m}^{2}$. EF tended to be lower in patients with a dominant $\mathrm{RV}$ than in patients with a dominant $\mathrm{LV}$ ( RV EF $54 \% \pm 14 \%$, LV EF $64 \% \pm 9 \%, P=.053)$. EF was significantly higher in the patients with an extracardiac conduit (Table 1). There were no differences in volumes and mass between RV and LV morphologic types. RV ESVI tended to be higher than LV ESVI, but this difference was not statistically significant $(P=.17)$.

Relative to reference data for ventricular volumes and mass, ${ }^{9}$ end-diastolic volume $(96 \pm 35 \mathrm{~mL}$ vs $87 \pm 31 \mathrm{~mL}$, $P=.017)$, end-systolic volume $(41 \pm 26 \mathrm{~mL}$ vs $24 \pm$ $11 \mathrm{~mL}, P<.001)$, and systemic ventricular mass $(91 \pm$ $48 \mathrm{~g}$ vs $72 \pm 33 \mathrm{~g}, P<.001$ ) were higher in patients. EF was lower in patients than in control subjects (systemic ventricle EF $59 \% \pm 12 \%$ vs LV EF $69 \% \pm 5 \%, P<.001$ ). Among patients, higher mass was associated with poorer $\mathrm{EF}(P=.027 ; \beta=-.11)$.

\section{NT-pro-BNP Levels}

Blood sample collection was successful in 28 patients. Median level of NT-pro-BNP was $11.5 \mathrm{pmol} / \mathrm{L}$ (2.9-57.0 pmol/L). Relative to reference studies for NTpro-BNP with an identical analysis method, ${ }^{10,11}$ mean NT-pro-BNP levels were higher than expected (mean NTpro-BNP in Fontan patients $18.0 \pm 15.2 \mathrm{pmol} / \mathrm{L}$, expected mean NT-pro-BNP $8.1 \pm 1.4 \mathrm{pmol} / \mathrm{L}, P=.002)$. Eight Fontan patients $(29 \%)$ had NT-pro-BNP levels above the upper reference limit (7 lateral tunnel TCPCs, 1 extracardiac conduit TCPC). Ages and follow-up times of these 8 patients did not differ from ages and follow-up times of the patients with NT-pro-BNP within the reference range. There were no differences in exercise response (maximum workload, maximum heart rate, $\dot{\mathrm{V}}_{2}$ max, OUES, oxygen uptake versus exercise intensity slope) or systemic ventricular volumes, function, and mass between patients with NT-pro-BNP above the 97.5th percentile and the remaining group.

NT-pro-BNP levels did not differ between patients with a dominant RV and patients with a dominant LV. NT-proBNP was lower in patients with an extracardiac conduit (Table 1). Univariable regression analysis did not identify any significant relationships between NT-pro-BNP and age, follow-up time, variables of exercise testing (heart rate increase, maximum workload, $\dot{\mathrm{V}}_{2} \mathrm{max}$, OUES, oxygen uptake versus exercise intensity slope), or MRI variables (EDVI, ESVI, EF, mass).

\section{DISCUSSION}

This study shows acceptable clinical conditions in a patient group 5 to 18 years after Fontan completion at younger than 5 years. In this patient cohort, all patients 
underwent TCPC, and this study group is therefore representative of the current treatment policy.

In our study, $68 \%$ of patients were in sinus rhythm, and no patients were receiving antiarrhythmic medication. Only 1 patient had frequent premature atrial contractions (and had atrial flutter shortly after this investigation), and no patients showed signs of clinically relevant sinus node dysfunction. Although patients with pacemakers were excluded from this study, they comprised only $7 \%$ of the complete cohort. The prevalence of arrhythmias after Fontan operation varies with the type of modification. The atriopulmonary connection has been identified as a risk factor by several groups, ${ }^{2,13}$ with a prevalence of atrial tachyarrhythmias at long-term follow-up of $29 \%$ in these patients. ${ }^{13}$ Prevalence of atrial tachyarrhythmias in lateral tunnel type TCPC is about $15 \%$ to $20 \%$ at midterm to long-term followup. $^{2,4,13}$ Although in theory atrial tachyarrhythmias should be less frequent with extracardiac conduit TCPC, prevalence has been reported to be as great as $11 \%$ in a large cohort at midterm follow-up. ${ }^{3}$ Other risk factors for development of atrial tachyarrhythmias are older age at Fontan completion, longer duration of follow-up, and early postoperative atrial tachyarrhythmias. ${ }^{4,13}$ In this study, all patients underwent Fontan completion younger than 5 years of age, a possible explanation for the absence of arrhythmias in this study group. Further follow-up, however, is necessary to determine the prevalence of arrhythmias long term after Fontan completion.

Although global ventricular function was good in this study, maximal exercise capacity was only $60 \%$ of normal. This is comparable to outcomes of maximal exercise capacity in 166 Fontan patients in a recent study from the Pediatric Heart Network. ${ }^{14} \dot{V}_{\mathrm{O}_{2}}$ max and peak heart rate in this study and our study were also comparable. The cause for impaired exercise capacity may be of cardiac, pulmonary, or muscular origin. Recently, we combined MRI with low-dose dobutamine stress testing to demonstrate an impaired preload reserve and an inadequate reaction of the pulmonary vasculature in Fontan patients. ${ }^{15,16}$ The resultant inability to increase stroke volume with stress testing could in part be responsible for the well-known impairment in exercise capacity. In contrast to others, ${ }^{17}$ we did not find a difference in exercise capacity between patients with a dominant $\mathrm{LV}$ or $\mathrm{RV}$, but our subgroups were small.

The OUES and the oxygen uptake versus exercise intensity slope are two measures of submaximal exercise that integrate the contributions of the cardiovascular, pulmonary, and muscular systems to exercise capacity. Because of their linearity, they are good indicators of maximal exercise capacity, even when maximal exercise is not possible or desirable. The OUES and oxygen uptake versus exercise intensity slope both indicate how effectively oxygen is extracted and used in the body. ${ }^{6,7}$ The steeper the slope is, the better the cardiovascular, pulmonary, and muscular systems work during exercise. The results in this study indicate a decreased efficiency of the system to extract oxygen, as was demonstrated by Giardini and coworkers ${ }^{8}$ in a small group of Fontan patients. As in that study, ${ }^{8}$ the relationship between $\log \dot{\mathrm{V}}_{\mathrm{E}}$ and $\dot{\mathrm{V}}_{\mathrm{O}_{2}}$ was not linear throughout the exercise test, but only for the second half of the exercise test. Therefore the OUES is not a good indicator of maximal exercise capacity in patients who manage to perform the exercise test only briefly (which was not the case in our study). Giardini and coworkers ${ }^{8}$ hypothesized that hypoxemia might be the cause of this nonlinear relationship.

There have been a limited number of studies on global ventricular function and volumes, as assessed with MRI, in patients after the Fontan operation. Recently, a large cohort of children was reported on by the Pediatric Heart Network. ${ }^{4}$ In that study, a subgroup of 161 children underwent MRI. Data in the Network study are not easily compared with other data, because they were indexed to $\mathrm{BSA}^{1,3}$ and a reference group is lacking. Anderson and associates ${ }^{4}$ showed a decrease in end-diastolic volume with increasing age and an increase in mass/volume ratio. There was no increase in ventricular mass with time as assessed with MRI. Echocardiographic data in that study suggest that the end-systolic volume is relatively large compared to end-diastolic volume ${ }^{4}$ which is in accordance with our findings. Eicken and colleagues ${ }^{18}$ reported normal volumes and mass and decreased EF in patients 10 years after Fontan completion (atriopulmonary connection, right atrium to $\mathrm{RV}$ conduit, or TCPC). After Fontan completion, dramatic changes in ventricular geometry occur. ${ }^{19,20}$ In the early postoperative period, there are decreases in ventricular dimensions and an inappropriate degree of ventricular hypertrophy. Although others have shown normalization of ventricular volumes and mass with increasing follow-up time, ${ }^{18,20}$ we demonstrated higher end-diastolic volumes, higher end-systolic volumes, higher ventricular mass, and lower EF in Fontan patients than in the control group. Our observations that the ventricle operates at an increased end-systolic volume with normal systolic blood pressure suggests that arterial elastance is increased.

Recently, Senzaki and colleagues ${ }^{21}$ found a higher ventricular afterload in Fontan patients than in patients with a biventricular circulation. These observations support experimental data from Szabó and coworkers, ${ }^{22}$ who demonstrated contractility-afterload mismatch in an animal model of the Fontan circulation. Earlier, we demonstrated well-preserved contractility with stress testing. ${ }^{15}$ This could explain the increase in ventricular mass (and increase in mass/volume ratio relative to control subjects) that we found in this group. As in patients with aortic valve stenosis, we found an inverse correlation of ventricular mass with $\mathrm{EF}{ }^{23}$ In isolated aortic valve stenosis, increased LV mass predicts the presence of systolic dysfunction and heart failure, and LV hypertrophy as a reaction to increased afterload may be maladaptive rather than 
beneficial. $^{23}$ Ventricular hypertrophy was also linked to diastolic dysfunction in Fontan patients by Penny and coworkers ${ }^{24}$ who found evidence for the development of uncoordinated ventricular relaxation. The effects of increased ventricular mass and the effects of contractility-afterload mismatch on the long-term function of the single ventricle must be investigated. Furthermore, together with the study by Senzaki and colleagues, ${ }^{21}$ our study provides data suggesting further clinical trials to investigate the effects of long-term afterload reduction on systemic ventricular function in the Fontan circulation.

Several groups have investigated BNP or NT-pro-BNP levels at short-term to midterm follow-up after the Fontan operation. ${ }^{25-29}$ In these studies, levels were increased relative to control groups, but the value of BNP or NT-proBNP seemed low for diagnostic or prognostic purposes. ${ }^{27}$ Only Hjortdal and associates ${ }^{29}$ found normalization of neurohormones late after the Fontan operation. Law and colleagues ${ }^{28}$ concluded that BNP could discriminate between patients with systemic ventricular failure (elevated BNP) and those with isolated cavopulmonary failure (BNP not elevated). Man and Cheung ${ }^{25}$ found a correlation between BNP and variables of diastolic function (most of their patients had undergone an atriopulmonary connection).

Under pathologic conditions, production of BNP rises strongly in both atria and ventricles. In our study group, systemic ventricular EDVI was only slightly higher than in the control group. Therefore BNP release from ventricular myocardial stretch is not to be expected. In this study, the number of patients with NT-pro-BNP levels above the upper reference limit was small, preventing us from proper analysis of NT-pro-BNP's usefulness for risk stratification in Fontan patients.

This study is limited by the size and characteristics of the study group. Because of the small numbers, comparisons between different Fontan types or between different systemic ventricular morphologic types should be made with caution. As in most studies of Fontan patients, the study group is heterogeneous, and conclusions therefore may not be applicable to all categories of patients. This group is not a representative random sample of the entire TCPC population, because we excluded patients with pacemakers and patients with neurologic complications. This limitation prevents us from making firm conclusions regarding the rhythm status of the overall patient group.

In conclusion, patients at midterm follow-up after a Fontan operation performed when they were younger than 5 years were in acceptable clinical condition, with preserved global ventricular function, moderately decreased exercise capacity, and NT-pro-BNP levels within the reference range. Systemic ventricular mass was elevated after the Fontan operation, however, suggesting contractility-afterload mismatch. The long-term consequences of this phenomenon for ventricular function merit further investigation.
We thank Dirk J. Duncker, MD, PhD (Department of Experimental Cardiology, Erasmus MC, Rotterdam, the Netherlands) for his contribution in the discussion on afterload mismatch.

\section{References}

1. de Leval MR, Kilner P, Gewillig M, Bull C. Total cavopulmonary connection: a logical alternative to atriopulmonary connection for complex Fontan operations. Experimental studies and early clinical experience. J Thorac Cardiovasc Surg. 1988;96:682-95.

2. d'Udekem Y, Iyengar AJ, Cochrane AD, Grigg LE, Ramsay JM, Wheaton GR, et al. The Fontan procedure: contemporary techniques have improved longterm outcomes. Circulation. 2007;116(11 Suppl):I157-64.

3. Giannico S, Hammad F, Amodeo A, Michielon G, Drago F, Turchetta A, et al. Clinical outcome of 193 extracardiac Fontan patients: the first 15 years. $J$ Am Coll Cardiol. 2006;47:2065-73.

4. Anderson PA, Sleeper LA, Mahony L, Colan SD, Atz AM, Breitbard RE, et al. Contemporary outcomes after the Fontan procedure: a Pediatric Heart Network multicenter study. J Am Coll Cardiol. 2008;52:85-98.

5. Koch A, Zink S, Singer H. B-type natriuretic peptide in paediatric patients with congenital heart disease. Eur Heart J. 2006;27:861-6.

6. Reybrouck T, Mertens L, Brusselle S, Weymans M, Eyskens B, Defoor J, et al. Oxygen uptake versus exercise intensity: a new concept in assessing cardiovascular exercise function in patients with congenital heart disease. Heart. 2000;84: 46-52.

7. Baba R, Nagashima M, Goto M, Nagano Y, Yokota M, Tauchi N, et al. Oxygen uptake efficiency slope: a new index of cardiorespiratory functional reserve derived from the relation between oxygen uptake and minute ventilation during incremental exercise. J Am Coll Cardiol. 2996;28:1567-72.

8. Giardini A, Specchia S, Gargiulo G, Sangiorgi D, Picchio FM. Accuracy of oxygen uptake efficiency slope in adults with congenital heart disease. Int J Cardiol. 2008;398: doi:10.1016/j.ijcard.2007.11.092.

9. Robbers-Visser D, Boersma E, Helbing WA. Normal biventricular function, volumes, and mass in children aged 8 to 17 years. J Magn Reson Imaging. 2008. In press.

10. Mir TS, Flato M, Falkenberg J, Haddad M, Budden R, Weil J, et al. Plasma concentrations of $\mathrm{N}$-terminal brain natriuretic peptide in healthy children, adolescents, and young adults: effect of age and gender. Pediatr Cardiol. 2006;27:73-7.

11. Albers S, Mir TS, Haddad M, Laer S. N-Terminal pro-brain natriuretic peptide: normal ranges in the pediatric population including method comparison and interlaboratory variability. Clin Chem Lab Med. 2006;44:80-5.

12. Connolly D, Rutkowski M, Auslender M, Artman M. The New York University Pediatric Heart Failure Index: a new method of quantifying chronic heart failure severity in children. J Pediatr. 2001;138:644-8.

13. Gelatt M, Hamilton RM, McCrindle BW, Gow RM, Williams WG, Trusler GA, et al. Risk factors for atrial tachyarrhythmias after the Fontan operation. J Am Coll Cardiol. 1994;24:1735-41.

14. Paridon SM, Mitchell PD, Colan SD, Williams RV, Blaufox A, Li JS, et al. A cross-sectional study of exercise performance during the first 2 decades of life after the Fontan operation. J Am Coll Cardiol. 2008;52:99-107.

15. Robbers-Visser D, ten Harkel DJ, Kapusta L, Strengers JL, Dalinghaus M, Meijboom FJ, et al. Usefulness of cardiac magnetic resonance imaging combined with low-dose dobutamine stress to detect an abnormal ventricular stress response in children and young adults after Fontan operation at young age. Am J Cardiol. 2008;101:1657-62.

16. Robbers-Visser D, Helderman F, Strengers JL, Kapusta L, van Osch-Gevers L, Pattynama PM, et al. Pulmonary artery size and function after Fontan operation at Young age. J Magn Reson Imaging. 2008;28:1101-7.

17. Ohuchi H, Yasuda K, Hasegawa S, Miyazaki A, Takamuro M, Yamada O, et al. Influence of ventricular morphology on aerobic exercise capacity in patients after the Fontan operation. J Am Coll Cardiol. 2001;37:1967-74.

18. Eicken A, Fratz S, Gutfried C, Balling G, Schwaiger M, Lange R, et al. Hearts later after Fontan operation have normal mass, normal volume, and reduced systolic function: a magnetic resonance imaging study. J Am Coll Cardiol. 2003;42:1061-5.

19. Rychik J, Jacobs ML, Norwood WI Jr. Acute changes in left ventricular geometry after volume reduction operation. Ann Thorac Surg. 1995;60:1267-74.

20. Fogel MA, Weinberg PM, Chin AJ, Fellows KE, Hoffman EA. Late ventricular geometry and performance changes of functional single ventricle throughout staged Fontan reconstruction assessed by magnetic resonance imaging. J Am Coll Cardiol. 1996;28:212-21. 
21. Senzaki Masutani S, Ishido H, Taketazu M, Kobayashi T, Sasaki N, et al. Cardiac rest and reserve function in patients with Fontan circulation. J Am Coll Cardiol. 2006;47:2528-35.

22. Szabó G, Buhmann V, Graf A, Melnitschuk S, Bahrle S, Vahl CF, et al. Ventricular energetics after the Fontan operation: contractility-afterload mismatch. J Thorac Cardiovasc Surg. 2003;125:1061-9.

23. Kupari M, Turto H, Lommi J. Left ventricular hypertrophy in aortic valve stenosis: preventive or promotive of systolic dysfunction and heart failure? Eur Heart J. 2005;26:1790-6.

24. Penny DJ, Rigby ML, Redington AN. Abnormal patterns of intraventricular flow and diastolic filling after the Fontan operation: evidence for incoordinate ventricular wall motion. Br Heart J. 1991;66:375-8.

25. Man BL, Cheung YF. Plasma brain natriuretic peptide and systemic ventricular function in asymptomatic patients late after the Fontan procedure. Heart Vessels. 2007;22:398-403.
26. Larsson DA, Meurling CJ, Holmqvist F, Waktare JE, Thilen UJ. The diagnostic and prognostic value of brain natriuretic peptides in adults with a systemic morphologically right ventricle or Fontan-type circulation. Int J Cardiol. 2007;114: 345-51.

27. Ohuchi H, Takasugi H, Ohashi H, Yamada O, Watanabe K, Yagihara T, et al Abnormalities of neurohormonal and cardiac autonomic nervous activities relate poorly to functional status in Fontan patients. Circulation. 2004;110: 2601-8.

28. Law YM, Ettedgui J, Beerman L, Maisel A, Tofovic S. Comparison of plasma B-type natriuretic peptide levels in single ventricle patients with systemic ventricular failure versus isolated cavopulmonary failure. Am J Cardiol. 2006;98:520-4.

29. Hjortdal VE, Stenbøg EV, Ravn HB, Emmertsen K, Jensen KT, Pedersen EB, et al. Neurohormonal activation late after cavopulmonary connection. Heart. 2000;83:439-43 